\title{
IDENTIDAD Y ALTERIDAD DESDE LA PERSPECTIVA CASHINAHUA*
}

\section{Els Lagrou}

Este artículo muestra el modo en que los cashinahua conciben la relación entre identidad y diferencia en su arte gráfica, en su sistema de mitades y en su filosofía marcada por un dualismo dinámico, donde el otro participa en la constitución del yo, y viceversa, y donde cada posición es siempre hipotética - y ritualmente reversible, posee claras cualidades perspectivistas. El estilo del pensamiento perspectivista implica una constante conciencia de la posibilidad de cambio de puntos de vista.

This paper shows how cashinahua's conception of the relationship between identity and alterity in their graphic art, their moiety system and their philosophy, marked by a dynamic dualism, where the other partakes in the constitution of ego, and vice versa, and where each position is always hypothetic - and ritually reversible, has clear perspectivistic qualities. The perspectivistis style of thought implies a constant awareness of the possibility of change of point of view.

Publicación original "Alteridade e identidade de uma perspectiva kaxinawa". Fazendo antropologia o Brasil. pp. 93-127. Orgs. Estreci, N., Fry, P. e Goldenberg, M. Rio de Janeiro: Capes, DP\&A Editora. 2001. Traducido del portugués por Luisa Elvira Belaunde. 
"La capacidad de imitar, e imitar bien, en otras palabras, es la capacidad de volverse otro" Walter BeNJaMín

"Siempre pensaba que para tener un mundo solamente necesitaba de dos cosas: el agua y la luz, el hombre y la mujer. Pero descubri que el mundo está hecho de tres. No basta tener el agua y la luz, se necesita tener el aire, que hace el viento, que da movimiento y que hace el lazo, hace con que las cosas anden. Es el tercer elemento que da vida. De esta manera, es también por causa de un hijo de la pareja que el mundo continúa" Acostinho ManduCA, cashinahua del río Jordão

La práctica diaria y ritual cashinahua revela un complejo y dinámico dualismo que pone en cuestión, insistentemente, una definición sustancialista de la identidad y de la diferencia. Por medio de recurrentes inversiones de papeles y posiciones en el sistema de nominación, y por medio de persistentes paradojas elaboradas por el discurso en el ritual, la cuestión de la identidad y de la alteridad aparece como el tema central de la ontología cashinahua.

Esta cuestión no es pertinente solamente para los cashinahua, puede ser encontrada en casi la totalidad de los grupos pano. Los pano son conocidos en la literatura etnográfica como especialmente "obsesionados" con los extranjeros y todos los tipos de "otros" (sobre este punto véase Erikson 19865; Keifenheim 1990, 1992 Calavia 1995). El intrigante concepto de Nawa, para el cual existen variaciones entre la mayoría de los grupos de lengua Pano, es paradigmático de la ambigüedad Pano con respecto a la definición de las fronteras entre el "yo" y el "otro".

Nawa puede ser usado como un término que denota una "verdadera" alteridad. enemigos, blancos y los mitológicos Inka (dioses caníbales). Personas o animales (cacería) son referidas en canciones rituales como Nawa, en el sentido de enemigo. Nawa es también utilizado para nombrar distintos grupos Pano (los Nawa del árez Juruá-Purús, incluyendo los cashinahua, yaminahua, y otros Nawa) o como par. del etnónimo atribuido a los pano vecinos, significando en este contexto "pueblo cashi (murciélago) -nawa yami (venado machado..) - nawua, mari (coti) - nawa Nawa, también puede ser usado para denotar una de las mitades o secciones donadores de nombres al interior del propio grupo (como entre los yaminah: marubo y amahuaca), teniendo el mismo sentido que el pluralizador - bu cashinahua utilizan este pluralizador para las generaciones alternadas de donado de nombres que constituyen su sistema onomástico: awvabu (los del tapir), you (los de la huangana), dunubu (los de la serpiente), kanabu (los del papagayo az awabuaibu (las mujeres que son del tapir), etc. 
Este hecho demuestra que, en las lenguas pano, un mismo concepto puede ocupar diferentes posiciones en una escala que va del polo de la completa alteridad y hostilidad hasta el polo del "nosotros", incluyendo el "yo", denotando pertenencia a una subdivisión que define el interior de la propia comunidad. Esto no significa, sin embargo, que el término nawa pierda su carácter relacional intrínseco. No importa cuanto nawa se aproxime de "yo", nawa siempre significará alguien que no es "yo mismo". Eso explica por qué el término no puede ser utilizado para auto-referencia o para referirse a alguien con quien se desea establecer un lazo de proximidad y pertenencia a un grupo. En este sentido, naw' "otro" que puede, fácilmente, ser transformado en "mismo" si es dotado del punto de vista del "otro".

La "noción filosófica de qué es ser igual y diferente" (Overing 1986b:142) es de especial interés para los amerindios y para los americanistas (Lévi-Strauss 1991; Maybury-Lewis 1979; Viveiros de Castro 1986; Carneiro da Cunha 1978.; Overing 1984; Clastres 1974, 1982). Esta noción, aparece en varios sistemas clasificatorios en la forma de complementariedad e interdependencia entre los sexos, expresando diferentes formaciones sociológicas y cosmológicas, en dualismos diametrales y graduales por todas las tierras bajas de América del Sur.

Los pano y los cashinahua en particular, presentan una variación en el colorido mosaico de las diferentes maneras de lidiar con la alteridad, ya que se sitúan en algún punto entre el concentrismo tupí y el diametralismo jé. En otras palabras, los Pano están entre los modelos sociales construidos para los amazónicos y las sociedades del Brasil central. Según Lévi-Strauss, en su caracterización de estas sociedades, los jé elaboran un sistema social dual bastante complejo que se "cierra" para el exterior por medio de la introyección de la diferencia. En estas sociedades, las dinámicas sociales son desempeñadas por medio de oposiciones y de antagonismos entre mitades, las cuales, cada una en su turno, hereda y fija atributos. Los sistemas sociales amazónicos y tupí, por otro lado, pueden ser caracterizados como sociedades "abiertas" que reducen la diferenciación interna para expresar mejor el antagonismo externo. De este último tipo de dinámica social resulta una red endogámica unida por medio de la guerra y del canibalismo.

Constatando la diferencia sociológica entre estos modelos, Viveiros de Castro (1993) les da el nuevo nombre de dispositivos para lidiar con la alteridad: "dualismo diametral" y "triadismo concéntrico". En el dualismo diametral, ejemplificado por el caso jé, en que lo exterior es incorporado por el interior, resultando en un sistema cerrado de mitades y en una rica y elaborada representación de este dualismo en rituales y la ornamentación, así como en las interacciones sociales cotidianas. El triadismo concéntrico, el segundo estilo de lidiar con la alteridad, puede ser clasificado como típicamente amazónico. Este modelo presenta un degradé entre el interior y el exterior, distinguiendo desde los otros próximos hasta el extranjero 
absoluto. Este tipo de definición de la identidad es extremamente contextualizado. Según el contexto de la discusión, otro grupo puede ser considerado de la misma identidad en oposición a otro común, o puede ser considerado otro en oposición a una más limitada definición de lo que significa "yo".

Los pueblos pano son un enlace perfecto considerando una tipología que contrasta las filosofías sociales amazónicas del este con las del Brasil central. Los Pano tienen un sistema de mitades ritualmente elaborado, pero su dualismo no es diametral: una de las mitades parece ser más exterior que la otra. La diferencia creada por medio de las clasificaciones dualistas entre los pano es de un tipo gradual, e hipotéticamente, reversible, no dicotómica o exclusiva del tipo de "A no es B". De esta forma, en el modelo formulado por Viveiros de Castro, este dualismo concéntrico tiende hacia un triadismo concéntrico, ambos representados en sistemas clasificatorios cosmológicos y sociológicos. Tomando en cuenta el carácter situacional de este modo de definir identidades, se puede hasta cuestionar la utilidad de un esquema triádico cuando se percibe la importancia del contexto y de la perspectiva indígena para dar cuenta de, y para nombrar, la identidad y la diferencia.

Entre los cashinahua, la pertenencia a una de las mitades y las cuatro secciones matrimoniales se da por medio de nombres personales (en este sistema de tipo Kariera existen cuatro secciones alternadas, conforme a la generación, que producen dos secciones para cada mitad, u ocho si es que cada una es dividida en líneas de género). En virtud de que los nombres pueden ser clasificados en grupos definidos por generación, sexo y mitad, estos funcionan como una guía de englobamiento étnico para escoger los términos de parentesco cuando se clasifica a un pariente previamente desconocido. Nombres y mitades son guías importantes para escoger las parejas matrimoniales o la pertenencia de los nombres a las generaciones alternadas parece ser menos importante que la pertenencia a la mitad, (véase McCallum, 1989)

Nos queda todavía, el deseado o prohibido "otro" real, que viene de fuera del orden social controlado. Este otro constituye el tercer elemento en la escala gradual que define el "yo" y el "otro", y es el potencial, hipotético, afín, omnipresente en el mito, el ritual, las canciones, las visiones, los sueños y las fantasías. El "otro real funciona como un valor cosmológico y escatológico que lo abarca todo y que nun ca es, y nunca podrá ser, presentado por medio de una alianza de matrimonio en estz vida terrenal. Los cashinahua son endogámicos, cuando es posible se casan en aldea. Esta práctica refleja su ideología concéntrica de casarse, por sobre todo, cor un pariente y no con un afín. Esta perspectiva encuentra respaldo en la ideolog: amazónica de la consustancialidad, producida por medio de la coresidencia y de comensalidad (el compartir las comidas), haciendo que las personas se sient pertenecientes a un mismo grupo.

La más inclusiva auto-definición para un cashinahua es nukun yuda, significa una persona que pertenece a "nuestro mismo cuerpo": un cuerpo que e 
producido colectivamente por personas que viven en la misma aldea y que comparten la misma comida. Son los parientes próximos los que provocan un fuerte sentimiento de pertenencia al grupo, y cuando están ausentes se siente su falta, expresada por el término manuaii, palabra usada para definir la nostalgia por la ausencia de un pariente cercano, y también para designar la sensación física y vital de necesidad de agua. El agua es vital para el cuerpo así como los parientes son vitales para constituir el "yo". Esta idea es ilustrada por la siguiente frase de Antonio Pinheiro: "Quien no siente falta de sus parientes, como se siente falta de agua, no es gente. Es un yuxin que se queda vagando por ahí".

Los lazos que unen a una persona a sus parientes constituyen el "yo" cashinahua. Esta red de lazos vitales es creada con el pasar del tiempo, al vivir juntos, al comer juntos por la comensalidad, el compartir determinadas sustancias vitales, baños medicinales y pintura corporal en los rituales. Las secreciones corporales y los olores afectan directamente a las personas con las cuales se vive. Una intervención, directa o indirecta, que transforma el cuerpo de alguien, afecta su mente, pensamientos y sentimientos. En este sentido, cuando los amerindios están hablando del cuerpo, están refiriéndose a un "yo" y a las transformaciones del cuerpo, a veces descritas como "alma".

Se puede decir, de esta manera, que el "yo" cashinahua es inclusivo, no solamente de su propio cuerpo sino de sus parientes próximos. Esto explica por qué una persona que no vive más en la aldea se vuelve más y más distante, y con el pasar del tiempo, se vuelve un no-pariente, o hasta un no-cashinahua a los ojos de quien estaba habituado a llamarlo de pariente. Esta persona puede hasta ser transformada en un no-indio, un nawa, o hasta perder los atributos humanos, volviéndose, por lo tanto, un ser que vaga, un yuxin, un ser sin forma. Sin forma, significa, en este contexto, no solamente un cambio de apariencia corporal sino de comportamiento y de pensamiento. Yuxin, en este contexto significa un ser perdido en el mundo, sin lazos, sin un lugar a donde ir, sin personas que se "acuerden" de él.

Esta transformación gradual de un Ser propiamente humano en un extraño y, finalmente, en un no- -humano o no-ser, acontece con el tiempo, por medio del comportamiento y el contagio con la alteridad. La misma lógica se aplica a la enfermedad. Estar enfermo significa estar en un estado transformativo de pérdida del "yo", adquiriendo alteridad. La fuente de la enfermedad no es producida por una única causa sino por una combinación de fuerzas internas y externas. Las fuerzas predatorias provenientes del exterior se vuelven activas dentro de una persona por medio de la comida ingerida o por los olores inhalados. También pueden entrar cuando una persona se encuentra en un estado emocional vulnerable, cuando se siente triste o solo. El proceso de convertirse en otro es complejo y es casi siempre reversible. Alguien deja de ser un "verdadero" cashinahua cuando ya no vive más en la aldea, cuando vive mucho tiempo en otros lugares, lo que lo lleva a adquirir 
un cuerpo diferente, y por medio de esta diferencia de cuerpo, a tener sentimientos, pensamientos, valores y memorias diferentes. Por lo tanto, ser propiamente humano, en el sentido cashinahua, significa vivir en comunidad con los parientes próximos.

Esta endogamia de la aldea apoyada en una fuerte ideología de la consustancialidad es complementada por una cosmología verticalizada, próxima del modelo araweté (tupí), en el que el deseo por la afinidad potencial es proyectado hacia el postmortem. Cuando una persona muere, el yuxin de su ojo adquiere un nuevo cuerpo y nuevas ropas capaces de transformarla en un ser inmortal que podrá casarse y vivir con los que los vivos representan como el polo extremo y absoluto del peligro, el "inconvivible" otro: los Inka.

Entre otros pueblos amazónicos, el orden social y el sistema de parentesco como una unidad interior compuesta de "elementos de una misma clase" (personas con un mismo cuerpo que comparten pensamientos y hábitos), son englobados por el orden cosmológico de la alteridad, del canibalismo, de la depredación. Su relación con este orden de fenómenos es temporal: Los humanos están en el camino de convertirse en otros, y este proceso, para las sociedades araweté y cashinahua, será completado solamente después de la muerte.

La complejidad de la relación entre semejanza y diferencia en la ontología cashinahua se manifiesta en el hecho que en su aparición expresada como un tema central en la mitología, es revelada en la racionalidad de la organización de la práctica ritual, en el discurso silencioso del arte visual, así como en el marco de referencia de la práctica clasificatoria cotidiana de los seres y las cosas. El pensamiento social cashinahua no proyecta la diferencia hacia afuera de la sociedad como hacen muchas sociedades amazónicas cuando intentan inventar una vida vivida solamente en la compañía de los iguales/parientes, por medio de la evitación de la terminología afín, y por la domesticación de todos los poderes y sustancias tomados del exterior. En función de una precisa preocupación con la depredación y una posible retaliación implicada en todos los actos creadores de vida y de comunidad, estos pueblos escogieron neutralizar a las expresiones inmanentes de violencia, reduciendo, de esta manera, el peligro implicado en cualquier actividad productiva (véase Overing 1985, 1993 para los Piaroa). Por otro lado, la ideología cashinahua tampoco no introyecta totalmente la diferencia como si ella emanase del interior, como parece suceder con la complementariedad del dualismo oposicional del sistema de las mitades jé y de su vida social y ceremonial.

La ontología cashinahua considera la alteridad como una dificultad y, en un: última instancia fatal, como una inescapable e insoluble paradoja: el único modo de concebirla es volverse, uno mismo, "otro". Sin volverse otro, por lo menos temporalmente, el ser está limitado a permanecer entre iguales, y esta posibilida permanece encerrada en los tiempos míticos de semejanza incestuosa y de separación 
de seres en diferentes tipos. Es apoyándose en esta concepción, que los cashinahua encuentran modos de "mímesis" y de transformación, diferentes modos de "cambiar de piel", actuando de esta manera, esta posibilidad de la alteridad que no es sino la preparación para la jornada final y la transformación después de la muerte en símbolo de semejanza y de extrema alteridad: el dios Inka.

La producción y reproducción de la alteridad por medio de la semejanza y de la semejanza por medio de la alteridad, un hecho observado por otros investigadores de las sociedades Pano (véase Erikson 986, 1992, Keifenheim 1990, 992, Calavia 1995, Townsley 1988), constituye una base para el argumento de este texto que percibe, por lo menos para los cashinahua, el artificio del dualismo como un medio para volverse uno en vez al inverso de dos, para volverse "mismo" y "otro". Las divisiones ontológicas son posicionales y temporales en esta visión del mundo: son relativas y cambiables, no esenciales o sustanciales, nunca fijas. Las diferencias no son de tipo oposicional sino de un tipo gradual.

A modo de ejemplo, podemos regresar, una vez más, a la figura de lenguaje nawa; nawa significa, en una secuencia clasificadora, el mayor representante de una especie, como nawan tete, el águila arpía, el mayor de los pájaros de presa; y la mitad asociada con el exterior es dicha la mitad del mayor de los elementos que constituye un par. Por ejemplo, comparando los dos tipos de jaguares conocidos por los cashinahua, el menor, txaxu inu (jaguar rojo) es clasificado como dua (la mitad del brillo, mitad ligada al mundo del agua), mientras que el mayor, inu keneya (el jaguar pintado) es clasificado como inu (la mitad del jaguar, mitad relacionada al Inka/mundo del sol).

La duplicidad de la figura del Inka es otro ejemplo de semejanza en la diferencia, o dualismo, usado para concebir la unicidad de un ser. Al inicio de mi investigación de campo, los cashinahua respondieron mis preguntas sobre el Inka de un modo explícitamente dualista: uno era el Inka pintsi, Inka hambriento de carne, un pueblo del tiempo histórico/mítico que canibalizaba a los cashinahua; el otro, totalmente diferente, era presentado como Inka Kuin, nuestro Inka, o propio Inka, en cuya aldea el yuxin del ojo pasa a vivir después de la muerte.

Con el pasar del tiempo, sin embargo, me di cuenta se hizo claro que la dualidad de la figura del Inka no es relativa a una duplicidad de personajes nombrados por el mismo término Inka, sino debido a la posibilidad de una duplicidad de puntos de vista y de relaciones, visto que estos dos Inka son uno; no son más que lados diferentes de una misma moneda. Inka puede ser tanto el avaro caníbal como el cónyuge proveedor a depender de la relación que se establece: afinidad real o afinidad potencial. De esta manera, ambas definiciones, de Nawa e Inka, sugieren una lectura del dualismo cashinahua a partir de la noción de perspectiva, una versión cashinahua de lo que vino a ser llamado el "perspectivismo amerindio". 
El dualismo es más un valor englobante para el pensamiento cashinahua que una discusión sobre la identidad. Cuando el "perspectivismo" es introducido en esta discusión, el dualismo adquiere un aspecto contextual y un carácter dinámico. La ontología cashinahua postula lo intrínseco, el inherente dualismo de todos los seres. Los seres vivos y la propia vida en el mundo, dependen de la mezcla de fuerzas y calidades opuestas. Todos los seres y las cosas del mundo son el resultado del ritmo y del control de la mezcla y presentan la dualidad fenomenológica del contenido y del contenedor, esqueleto y piel, semilla y cobertor.

Cualquier separación absoluta de clases diferentes significa ausencia de vida, mientras que su mezcla induce el movimiento, lo que, a su vez, indica vida. El mito de origen del orden del mundo comienza con la creación del día y de la noche. Antes de que existiese el mundo, estas calidades estaban, como todas las calidades, latentes pero separadas, "durmiendo en sus respectivas cavernas". Era el tiempo de antes del tiempo, cuando nada cambiaba porque nada era mezclado; no había interacción de ninguna especie entre las calidades de los seres de diferentes clases. La diferencia fue creada por medio del acto de su revelación, cuando los seres primordiales abrieron las cavernas del amanecer y del anochecer: la caverna donde el sol se escondía y la otra que guardaba el frío en su interior (Capistrano de Abre: 1941). La creación vuelve accesible a los sentidos las posibilidades del ser.

El primer principio organizacional del mundo fue la mezcla de la oscuridad con la luz a lo largo de una escala de tiempo que introduce el día y la noche, tiempo para trabajar y tiempo para dormir y soñar. El arco-iris es un símbolo clave de esta mezcla. Los colores de la vida, amarillo y verde/azul, así como el color rojo/amaril más problemático (todos los colores están compuestos de estos colores primarios derivados de las palabras que expresan estados de crecimiento), son el resultado de la revelación de la potencialidad de la forma y del ser escondida en la oscuridad pot medio de la luz.

Las canciones rituales pueden ser leídas tanto en un registro social relacionat: al parentesco y a la afinidad (los problemas en lidiar con la alteridad), como en ut registro más abstracto relacionado a la ontología - la calidad y el estado del ser y los seres - que presenta imágenes poéticas, de valor englobante, del intrínse entrelazamiento de todos los cuerpos y materias en la tierra por medio de la creaci: y de la depredación, del contagio, de la mezcla de las calidades. "Lo que es comi come, en el mismo momento en que es comido", "lo que come se transforma en lo qu: es comido" (o "usted es lo que come") pero, también "usted come lo que usted es"

Lo que distingue este proceso de vida no es la diferencia entre agencis ausencia de agencia, sujeto y objeto, sino una diferencia de contexto y de poje relativo. Debido a que cada ser existe simultáneamente en ambos niveles de material y de lo inmaterial, cada ser es capaz de agencia, de percepción, subjetividad. Para tener forma y consistencia, la materia necesita estar imbuida 
yuxin, ya que «sin yuxin, todas las cosas se vuelven polvo, solamente una cáscara vacía. Usted las toca y ellas se disuelven y entonces usted ve solamente cenizas, polvo" (Antonio Pinheiro, 1989). La definición de un ser como un verdadero yuxin o una mera "cosa" depende, nuevamente, de una escala gradual en la que A necesariamente implica $B$, al inverso de un par diametralmente opuesto en el que para ser A, A no puede ser B.

Lo que define la situación (y tiende a ser un principio que guía la clasificación de los seres a lo largo de una escala desde lo menos hasta lo más peligroso) es lo que inicia el proceso de intercambio y/o depredación, un proceso que transforma las partes involucradas. Toda acción de interrelación, intercambio de palabras y sustancias, desencadena un proceso que, a su vez, produce otros procesos, de esta manera el mundo se encuentra en permanente movimiento.

Podemos concluir que si bien según el dualismocashinahua A, necesariamente, implica B, las oposiciones en el pensamiento y en la acción existen solamente para ser disueltas. Esta disolución de la dualidad puede ser alcanzada siguiendo la lógica temporal (encontrada en la mitología cashinahua y en la escatología) o en la lógica de la depredación. En este sentido, el problema de la semejanza y de la diferencia en la ontología cashinahua parece resultar en una solución encontrada en la continuidad de los términos opuestos, al inverso de su mutua exclusión. Por esto, la diferencia no puede ser definida simplemente en términos de una complementariedad de categorías opuestas, sino en términos de un movimiento en dirección hacia la integración. El dualismo cashinahua es menos una clasificación de las cosas y de los seres que un problema, una cuestión a ser resuelta.

\section{La perspectiva cashinahua}

"El fenómeno humano es una idea única y coherente, organizada mental, fisica y culturalmente alrededor de la modalidad de percepción que llamamos 'significado'"

ROY WAGNER

"El ojo que existe es el que ve" CHICO CÉSAR

En los últimos veinte años, algunos autores llamaron la atención sobre el carácter no-esencialista de la visión del mundo amerindio. La inclinación filosófica amerindia podría ser "nominalista" contraria al "realista" (Overing 1990; Seeger, da Matta \& Viveiros de Castro 1979). La introducción de la noción de perspectivismo da un paso más allá en el proceso de comprender el significado de las afirmaciones nativas. A grosso modo, el perspectivismo indígena significa que el mundo (la realidad) que se ve depende de quien la ve; de donde se ve, y con qué intención, 
determinado ser mira a otro ser. En este sentido, el fenómeno de la perspectiva, bien conocido por los americanistas, puede ser colocado del siguiente modo: los animales se ven como humanos así como los humanos ven a los animales como presas de caza; los humanos se ven como humanos y son vistos por determinados espíritus como presas de caza. Este es el significado de una afirmación comúnmente escuchada que afirma que determinados animales "son gente" (Gow 1988). Los humanos pueden, frecuentemente, cambiar su punto de vista con relación a los animales cuando estos son perseguidos delante de sus ojos durante una expedición de cacería. Estas transformaciones están presentes en la mitología amazónica y son cruciales en la experiencia cotidiana (aún más durante la noche). Desde hace tiempo, los estudiosos del chamanismo amerindio (Baer \& Langdon 1992; Chaumeil 1993; Overing 1990; Crocker 985) notaron que esta capacidad de mudar esta percepción es una capacidad específica del chamán, pero ahora podemos fácilmente reconocer esta característica como un principio estructurante que no se aplica solamente al chamanismo como un campo aislado del pensamiento y de especialización, sino a la ontología amerindia como un todo.

Esta referencia básica, que presupone la transformabilidad del mundo, puede ser encontrada en todos los campos de pensamiento y de acción cashinahua. Con la muerte, la persona transforma su cuerpo (un proceso expresado en términos de un cambio de ropas, de una transmutación de calidad), transformándose en un Inka, el símbolo arquetípico de la alteridad. En los rituales colectivos de ingestión de la bebida alucinógena ayahuasca (cipó, nixi pae, nawa himi), el bosque y sus animales se transforman en humanos y espíritus para los que tomaron la bebida. Los árboles y sus habitantes, por otro lado, se transforman en ciudades ante los ojos cerrados del que se transforma en la anaconda / ancestro mítico Yube al beber su "sangre" - así como es llamada el ayahuasca. La lógica de transformación de una sustancia animada en otra está presente aún en los actos más simples, como comer: cuando alguier come maíz, por ejemplo, se transforma en maíz y el maíz se transforma en parte de la persona (de manera semejante a la descrita por Isacsson para los Emberá y po: Lima para los Juruna).

Parece posible relacionar mi propia percepción de la "calidad perspectiva" del pensamiento amerindio (en la aceptación de esta expresión utilizad primeramente por Arhem 1993), está relacionada a la discusión en curso entre antropólogos y otros investigadores sobre el significado y el uso correcto de metáfora (Overing 987; Crocker 1977; Goodman 1978; Ortony 1993; Ricoeu1981).(Århem, 1993, 1996) o 'perspectivista' (Viveiros de Castro, 1996) de pensamiento amerindio a la discusión en curso, llevada a cabo por antropólogos otros científicos sociales, sobre el significado y el uso propio de la metáfora, realizad por antropólogos y otros científicos (Overing 1985a , 1987; Crocker 1977; Goodm1978; Ortony 1993; Ricoeur 1981). 
En su formulación de una teoría sobre el perspectivismo amerindio, Viveiros de Castro $(1996,2002)$ observa que el pensamiento perspectivista opera con una lógica simétricamente inversa a la lógica utilizada por el relativismo cultural occidental, según el cual cada cultura tiene su propio punto de vista sobre una naturaleza fija. En el caso amerindio, se trataría de naturalezas múltiples y cuerpos percibidos por una sola consciencia, un solo punto de vista del humano en tanto que agente. Si se considerase a la metáfora como una figura de lenguaje figurativa, que sólo representa y no presenta este instrumento de lenguaje, esta pertenecería primeramente a la lógica relativista occidental antes que a la lógica transformacionista amerindia. En cambio, el acercamiento a la metáfora que propongo aquí toma en cuenta el valor agencial del punto de vista de la acción como del habla, el habla a través de metáforas, donde estas acciones sobre el mundo, o sobre los mundos interconectados de los diferentes seres y estados de ser ayudan a hacerlos en términos bien concretos, moldeándolos y transformándolos. De este modo, para los Cashinahua, el mundo se encuentra en un permanente estado de peligrosa fluidez de la forma, hasta que intervenciones decisivas, entre las cuales el habla y la voz, le den forma fija a los perceptos.

Una lógica simétricamente inversa utilizada en el relativismo cultural occidental, donde cada cultura tendría su propio punto de vista sobre una naturaleza determinada. En el caso amerindio se trataría de múltiples naturalezas y cuerpos percibidos por una sola consciencia, un solo punto de vista, el del humano en cuanto agente. Si se considerase la metáfora como una figura de lenguaje que solo representa y no presenta, este instrumento de lenguaje pertenecería antes a la lógica relativista occidental que a la lógica transformacionista amerindia. Entretanto, el abordaje a la metáfora que propongo aquí toma en cuenta el valor agencial tanto del punto de vista de la acción y del habla, el habla a través de metáforas, donde estas acciones sobre el mundo (los mundos interconectados de diferentes seres y estados de ser) ayudan a hacer en términos bien concretos, moldeando(los) y transformando(los). De este modo, para los cashinahua el mundo se encuentra en un estado permanente de peligrosa fluidez de la forma, hasta que intervenciones decisivas, entre las cuales el habla y la voz, dan forma fija a los preceptos.

La discusión en torno a la metáfora llama la atención hacia el papel cognitivo de la semejanza en la metáfora y en el pensamiento en general, en este sentido reevalúa, aunque de forma indirecta e implícita, algunas de las contribuciones de LéviBruhl (Cardoso de Oliveira 1991; Goldman 1993) a propósito del animismo en el "pensamiento primitivo". (Cardoso de Oliveira 1991; Goldman 1993).

El uso estructuralista de la metáfora según la tradición Lévi-Straussiana, enfatiza solamente la capacidad diferencial de la metáfora como analogía, dejando de lado la lectura literal y polisémica de los complejos contenidos de las afirmaciones indígenas, que cobran sentido cuando se toma en cuenta el contexto específico de 
referencia. Las declaraciones pueden comunicar más que equivalencias estructurales cuando, por ejemplo, un bororo dice "mi hermano el papagayo" (Crocker 1977) o un cashinahua afirma que "la anaconda es nuestra ibu (padre/madre)".

'Lévi-Strauss revela un aspecto preeminente de la lógica clasificatoria tribal: la analogía, donde en sus palabras (1963:77): ino son las semejanzas, sino las diferencias las que se asemejan 'que importan, o sea, el cuervo es para el gavilán real lo que el clan A es para el clan B. El 'primitivo'no reivindica un lazo místico ni de sangre con su tótem y por lo tanto no cree en la semejanza en que se podría pensar que cree cuando llama a su vecino de papagayo o de cuervo. Una consecuencia de la comprensión Lévi-Straussiana de la metífora es que euade el análisis de la semejanza (la relación entre mi vecino y un papagayo) la cual es a fin de cuentas, tan crucial para la comprensión de las afirmaciones metafóricas como las diferencias y analogías". (Overing 1985:153. Traducción propia).

Los estudios recientes sobre la metáfora (Ricoeur 1981; Shanon 1993; Lakoff 1990) revelan que todo lenguaje es, a fin de cuentas, metafórico y polisémico en el proceso continuo de atribuir significado a la experiencia, conectando imágenes conocidas y conceptos previamente no relacionados, creando de esta manera nuevos campos. El proceso cognitivo necesita de estos instrumentos creativos para ser capaz de cruzar la fosa entre realidades conocidas y desconocidas, y de nombrar nuevas experiencias y percepciones. Nuevos mundo son imaginables por medio del lenguaje metafórico, y esto atestigua por qué la metáfora es indispensable tanto para el científico como para el antropólogo, así como para el artista, ya que su trabajo es metafórico y metonímico, asociativo y englobante.

Lo que une la ciencia al arte en el uso de la metáfora es el cambio de nuestra visión y conocimiento del mundo, una vez que nuestra visión cambia, el mundo nunca más será el mismo. Este es un el lazo preformativo que conecta el lenguaje y la percepción al mundo. El mundo exterior es un mundo imaginable, perceptible, experimentable, y por lo tanto, lleno de sentido para nosotros. Es nuestra perspectiva incorporada, contextualizada y, por esto, cambiable sobre el mundo que hace que el mundo sea lo que es. Y, de esta manera, existen múltiples mundos (Goodman 1978). Como veremos, esta percepción filosófica es llevada más lejos por el pensamiento amerindio que por nuestra tradición de pensamiento.

Si las metáforas representan nuestra "apertura al mundo", utilizando una expresión gadameriana, entonces necesitamos ser lo más reflexivos posible sobre las metáforas que usamos. Las metáforas son usadas para conectar diferentes dominios, diferentes mundos, creando un nuevo mundo por medio de la "fusión de horizontes" (esta imagen implica mutualidad y no un movimiento unidireccional, por lo tanto, es algo inherentemente intersubjectivo). Las metáforas se vuelven una limitación para el entendimiento del "otro" cuando las reificamos, cuando se vuelven 
un medio para reducir la ansiedad experiencial y cognitiva provocada por la confrontación con el sin sentido.

Cuando se está en territorio seguro, La pesadilla de enfrentarse a la inconmensurabilidad es necesaria para desvelar nuevas metáforas y conexiones, inimaginables cuando se está en territorio seguro. Las metáforas fracasan en su intento de producir comprensión cuando aniquilan diferencias, reduciendo la diferencia a la semejanza. Cuando son bien escogidas, las metáforas crean nuevos mundos, funcionando como "puentes" capaces de estar próximas de la experiencia del sujeto que tentamos evocar, y al mismo tiempo, próximas de la experiencia, a nivel imaginativo, de la comunidad de posibles lectores para quienes estamos escribiendo.

En su un artículo reciente, Viveiros de Castro (1996) sitúa su acercamiento al "perspectivismo amerindio" dentro de la paradoja clásica naturaleza/cultura heredada del americanismo de Lévi-Strauss. Viveiros de Castro intenta demostrar cómo es que categorías como "humano", "animal", "alma" son "categorías perspectivas" para los amerindios, y deben ser analizadas en términos de una teoría de los signos. El punto de vista define el lugar ocupado por el sujeto. Usando una reflexión de Deleuze (1988:27), Viveiros de Castro (1996:11) define el perspectivismo de la siguiente manera:

Tal es el fundamento del perspectivismo. No expresa una dependencia con respecto a un sujeto previamente definido, sino al contrario, será un sujeto aquel que acceda al punto de vista (Viveiros de Castro 1996:11).

$Y$ del sujeto al "alma" no hay sino un paso: "Tiene alma quien es capaz de un punto de vista" (1996:1). Si lo que define la humanidad es la idea de un sujeto como un punto de vista, lo que une lo humano a lo animal no es su animalidad común sino su misma humanidad. Tener un cuerpo es algo inherente a la capacidad de un punto de vista, y este cuerpo situado e incorporado de agencia, define como el mundo es percibido. No es solamente la morfología del jaguar que define su identidad como un ser-jaguar, sino también su comportamiento, su intención y su manera de percibir el mundo a través de la perspectiva de la depredación. Esto es lo que hace que un ser humano se transforme en jaguar: cuando adquiere el "estado" de jaguar.

Lo que estoy llamando cuerpo, por lo tanto, no es un sinónimo de una fisiología distintiva ni de una morfología fija; es un conjunto de afecciones o de modos de ser que constituyen un hábito. Entre la subjetividad formal de las almas y la materialidad sustancial de los organismos, hay un plano intermediario que es el cuerpo como un haz de afecciones y capacidades, y que es el origen de las perspectiva (1996:13.)

De la misma manera, el uso frecuente que hacen los amerindios de autodesignaciones, para ellos mismos y los pueblos emparentados como "verdaderos o 
propiamente humanos" (en el caso cashinahua) no tiene por intención denotar la humanidad como una especie natural, sino como una condición, la condición de persona, de sujeto y de ser social. En este sentido, los etnónimos deben ser entendidos como pronombres y no como sustantivos (Viveiros de Castro 1996:0).

La relación de depredación es una de las situaciones en que más se percibe la contextualidad y reversibilidad de la identidad en la pareja depredador/presa. Un ejemplo etnográfico, cercano al acercamiento del perspectivismo amerindio presentado más arriba, es el caso wari (Vilaça 1992), en que la depredación aparece como una metáfora clave para las relaciones y creaciones de identidades entre humanos y no humanos. Para los wari, ser humano significa estar en la posición del cazador, mientras que ser animal significa ocupar una posición de presa. Para los animales y los espíritus que depredan a los humanos, los humanos son percibidos como animales. En este sentido, la identidad humana es identificada a la agencia, $y$ es más, la agencia es identificada al acto de la depredación.

De esta manera, la oposición ontológica fundacional en la designación de los diferentes seres está constituida por la oposición entre cazador y presa, una oposiciór: que define las calidades contrastantes del sujeto y del objeto dentro de una continua actividad depredativa. Esta actividad es considerada omnipresente en cualquier tiempo e implica, por su propia dinámica de ataque y represalia, la inherente posibilidad de inversión de las perspectivas y de los papeles, según los cuales el cazador se vuelve la presa.

Esta misma lógica fue observada con respecto a la guerra entre algunos pueblo: amazónicos (Fernández 1970; Viveiros de Castro 1986, 1992). Pienso que esta lógica refleja una ideología igualitaria implicando la conciencia de la semejanza esencia de calidad, capacidad y valor del enemigo (presa). Tarde o temprano, lo que es cazado irá a cazar. Lo que es comida irá a querer comer al que se lo comió (pot medio de la enfermedad, por ejemplo). Los cashinahua comparten esta visí́ perspectiva de ser cazador, para algunos, y ser presa, para otros, o cazador y pre para los mismos seres en diferentes momentos y contextos. También extienden es relación para las plantas y los árboles (como lo hace la mujer achuar, de manera ma radical, con las "plantas caníbales", Descola 1987).

Todos los seres están implicados en esta red de acciones y contra-acciones la depredación, alimentación y transformación de los seres vivos en materias la producción de vida. La idea abstracta, de que para crear vida es necesario destr. algo o alguien, es concreta y vivida en los estilos de vida de las sociedades cazadores-recolectores, en las cuales es necesario constantemente domar las fuer "salvajes y ocultas" del bosque, conquistando de esta manera pequeños espaci controlados por los humanos. 
Pienso, sin embargo, que estas fuerzas interdependientes de lucha no deben de ser entendidas en términos del par naturaleza/cultura. Mi entendimiento deriva de una exégesis cashinahua del mundo, que lo considera imbuido de todas las calidades posibles o imaginables de agencia, intencionalidad y perspectiva. La siguiente declaración por Agostinho Manduca ilustra, literalmente, esta visión: "La tierra está viva, usted sabe; una cosa está transformándose en otra". Complementando esta declaración, Augusto Feitosa nos dice: "El bosque tiene sus ibu (progenitor, creador, dueño, guardián, sembrador), todo tiene su ibu".

Para los cashinahua, la alteridad no significa la falta de humanidad, subjetividad o agencia sino la inteligibilidad y diferentes modos de percibir y mirar las cosas, implicando lo relacional y nunca lo esencial o substancial. Los dioses caníbales Inka, los "blancos" y los enemigos no son vistos como intrínsecamente caníbales incontrolables o bestias-fieras. Se comportan de esta manera no en función de una calidad inherente, sino en virtud de un determinado tipo de relación, una relación de exceso de alteridad, más de la que un "yo" puede aguantar. Una vez más, para ser capaz de lidiar con la alteridad se debe aprender a volverse en otro, o imitar el ser otro, en el sentido de captar su punto de vista sobre el mundo, y de esta manera, adquirir poder sobre la situación interactiva.

A pesar de expresar posiciones reversibles entre presa y depredador de manera semejante a los wari, la oposición ontológicamente fundadora para los cashinahua divide el mundo de un modo diferente. El tema central es la relación entre el "yo" y el "otro", huni (nosotros, propiamente humanos) y nawa (otro, enemigo potencial). Esta relación no denota una reversibilidad de posiciones en que el sujeto significa agencia y el objeto pasividad, sino una intersubjetividad en que ambas posiciones presentan la calidad de agencia y de subjetividad. Esto parece explicar por qué el término nawa puede ser presentado, al mismo tiempo como el depredador más poderoso y como la víctima humanizada de una expedición de cacería: es un enemigo que significa, al mismo tiempo, víctima y agresor. Como resultado de este proceso, se percibe una ontología en que los seres asumen una posición subjetiva; la diferencia está entre lo conocido, la agencia propiamente humana (social) y lo desconocido, la agencia impropia y anti-social. A un nivel sociológico el problema es, una vez más, el de la afinidad.

Otro elemento presente en todas las relaciones, y en este punto regresamos a Lévi-Strauss (1991) y Dumont (1980), es que en relaciones antagónicas entre diferentes seres (y todos los seres son diferentes) siempre hay un desequilibrio de poder, a pesar de que este ser es hipotéticamente reversible. Esta visión es expresada por el lugar que ocupan los mellizos en el pensamiento amerindio. En la mitología amerindia, los mellizos nunca son pensados como idénticos, como gemelos propiamente dichos, sino como mellizos diferentes. Su diferencia es colocada desde el inicio, considerándose un hecho incontestable, un hecho lleno de consecuencias, 
o sea, uno de los mellizos nace primero. De este hecho derivan todos los tipos de diferencias, no posicionales sino graduales. Entre los mellizos hay uno más grande y otro más pequeño, uno más fuerte y otro más débil, y un aspecto que todos mis informantes subrayaban, hay uno con suerte y otro con mala suerte. Esta lógica de la diferencia gradual, del más viejo y el más joven, reposa sobre la base del dualismo de las mitades y sobre toda la concepción de la complementariedad en las relaciones y el mundo.

En el pensamiento amerindio, la idea de doble implica, por lo tanto, la diferencia. La duplicidad en la singularidad es posible. Lo que no es posible es la igualdad en la duplicidad. La idea es la creación de seres de una misma clase, significando semejanzas suficientes para garantizar el entendimiento entre ellos, no clones ni réplicas. Una simetría perfecta no será nunca encontrada en el mundo. Esta idea se encuentra en el arte cashinahua. La simetría en el arte es rectificada por un pequeño detalle asimétrico que conlleva la idea de identidad distinta. Es el detalle, la disonancia, que da vida al trabajo artístico, así como a la vida misma. De esta manera, el estilo gráfico cashinahua puede ser visto como la visualización del valor social de la autonomía personal que se manifiesta en sutiles detalles idiosincráticos, escondidos en el patrón global de simetría e igualdad. El efecto studium-punctum: descrito por Roland Barthes (1980) se aplica a este estilo gráfico.

El studium o su discurso dominante, sería en este caso la repetición de elementos iguales en un ritmo simétrico y el alto valor dado a la ejecución delicada de finas líneas paralelas. El estilo gráfico cashinahua es caracterizado por el horro: al vacío: toda la superficie de los cuerpos pintados debe ser cubierta con los diseños y ninguna línea puede quedar abierta. El padrón puede ser cortado donde la superficie pintada termina, sugiriendo una continuación del mismo padrón más allá de ese soporte. Esto demuestra la función del diseño como algo que une más de lo que separa. El diseño visualiza la calidad yuxin (fuerza animadora) que esta infundida en el mundo cashinahua, separándolo de los pueblos sin (una miradis hacia el) diseño.

El punctum es la disonancia cercana del detalle invisible, la sorpresa necesaria para la dinámica visual, lo que da vitalidad estética al todo, que se manifiesta corr: una pequeña diferencia en el padrón repetitivo, un punto asimétrico al interior una simetría. Debe de existir cierta homogeneidad entre los elementos visuales pars que la pequeña diferencia sea capaz de tocar nuestros ojos. El arte cashinahua explorz elegantemente el entrelazamiento del studium y del punctum. De esta forma, primera impresión que dan para un tejido o un rostropintado, es la primera impresíc que darán de una superficie cubierta por un padrón geométrico por medio de infinita repetición de unidades iguales. Una mirada más fina percibirá que uno los rombos del padrón colmena tiene un ángulo más que los otros. Este es el punc: y su presencia en el arte cashinahua es sistemática (Dawson 1975, nota la ocurrende detalles asimétricos en los tejidos cashinahua). Otro ejemplo de este fenómenos 
encuentra en los collares. Si un collar de cuentas, por ejemplo, está compuesto de la alternancia de seis cuentas rojas y seis azules, en algún lugar en el medio del collar se encontrará una cuenta blanca perturbando, a propósito, la perfecta simetría de la repetición del padrón.

Esta marca sutil de la personalidad del artista en las piezas fuertemente marcadas por un estilo, parece congruente con la manera en que los cashinahua experimentan la vida: crear comunidades es el fruto del fuerte deseo de vivir tranquilamente con parientes cercanos, volviendo la sociabilidad posible por medio de la autonomía personal y el respeto por la autonomía ajena.

El estilo de pensamiento perspectivo implica una constante conciencia de la posibilidad de cambiar de puntos de vista, consecuentemente, cambiando la mirada sobre el mundo. Como es de esperar, esta misma actitud perspectivista puede ser encontrada en los sistemas de los diseños amazónicos. La calidad cinética de cambiar de perspectiva entre el fondo y la figura, cuando se observan los padrones laberínticos típicos de los tejidos y la cestería de muchas sociedades amazónicas, fue resaltada por Roe y Guss en sus análisis del "arte abstracto" amerindio.

Peter Roe llamó la atención sobre la correspondencia entre estilo artístico y estilo de pensamiento. El autor también dice que la "ambigüedad visual" de los diseños shipibo corresponde, en su sistema de pensamiento, a un "énfasis sobre la ambigüedad mental" (Roe 1987:5-6). La "ambigüedad mental" es una expresión problemática pero puede ser fácilmente sustituida por la del perspectivismo, no obstante, transforma el significado primordial de esta analogía. Para Roe, la significación de la ambigüedad perspectiva en el arte indígena "abstracto" reposa sobre el hecho que este arte revela la actitud cognitiva del artista y del público. Para los amerindios el universo es transformativo. Esto significa que la visión puede repentinamente cambiar delante de nuestros ojos. El mundo está compuesto por muchas capas de mundos, y los diversos mundos son concebidos como simultáneos, presentes y en contacto, aunque no siempre perceptibles. El papel del arte es el de comunicar una percepción sintética de esta simultaneidad de las diferentes realidades.

Al analizar los diseños indígenas, Roe llama la atención sobre el padrón estilístico y no sobre las unidades aisladas constitutivas del padrón. Mi investigación sobre el significado de los diseños entre los cashinahua confirma las percepciones de Roe. Cuando una lectura iconográfica de las unidades aisladas parece confusa y contradictoria, es necesario introducir una lectura más estructural de los padrones como un todo, lo cual, en el caso cashinahua, proporciona una mejor comprensión de sus usos y significados. Las analogías entre este código visual y los otros códigos verbales, y no verbales, que juntos forman el tejido de fondo para la significación cognitiva y emocional del estilo artístico, son esenciales. En este sentido, estoy convencida que un acercamiento al arte especializado es improductivo. La estética 
debe ser englobada dentro de la hermenéutica en el estudio del arte indígena así como en el arte occidental.

Otra ilustración de la presencia del perspectivismo en el arte amazónico puede ser encontrada en el estudio sobre los mitos, la cestería y las canciones yekuana (grupo karib de Venezuela) realizado por David Guss (1989). Después de abandonar la búsqueda de los grandes mitos de origen yekuana (que sabía existían por haberlos visto en textos antiguos), el autor decidió, desesperadamente, sentarse con los ancianos para aprender el arte de trenzar cestos. Lo que descubrió de esta manera fue que la vida para los yekuana es como un trenzado, o en otras palabras, que el trenzar es una metáfora clave de la vida, y que fragmentos y partes del mito de origen eran trenzados, proferidos y cantados por los viejos todos los días durante el crepúsculo, cuando se sentaban juntos en círculo.

El conocimiento no puede ser adquirido fuera del contexto, ya que el conocimiento en estas sociedades es una parte constitutiva de la persona: conocimiento y memoria son incorporados y actualizados en la medida en que dan sentido a la creación de la vida cotidiana (véase Gow 1991). En este sentido, nuestros valiosos descubrimientos durante el trabajo de campo no suceden de una manera tan accidental como solemos pensar. Surgen cuando nuestros profesores nos consideran maduros para entenderlas, o simplemente, cuando se presenta el contexto cierto, un contexto capaz de revelar no solamente el contenido, sino también la significación y el sentido práctico, moral y emocional de un determinado conocimiento.

El resultado de la iniciación de Guss a las técnicas del trenzado yekuana resultó en un profundo entendimiento de la ontología yekuana:

Con los diseños abstractos este retrato simultáneo de una realidad dual se vuelve mucho más complejo (que en el caso del diseño figurativo). Aqui también se muestra la imagen y la contra-imagen. Sin embargo, lo que es realmente representado es la relación dinámica entre los dos. A diferencia de las imágenes estáticas de los diseños figurativos, la estructura cinética de estas formas crea un mozimiento sin fin entre los elementos diferentes, jalando al espectador hacia dentro de ellas. La percepción entonces se vuelve un desafio, con el espectador siendo forzado a decidir cual imagen es real y cual es una ilusión. La dualidad significada por la conquista de los cestos es perceptualmente incorporada en la estructura de sus diseños. Aquí todas las oposiciones en la cultura (femenino y masculino, visible y oculto, creativo y depredador, veneno y comida) son visualmente resueltas. No obstante, esta no es una resolución estática. Es como la vida cotidiana de todo yekuana, una interacción constante entre las formas físicas y las invisibles que las impulsaron (Guss 1989:122).

El estilo general del diseño cashinahua, llamado kene kuin (diseño real), usado en la pintura corporal, la cestería, la cerámica y el tejido es similar al estilo del trenzado 
de los yekuana. El juego entre imagen y contra-imagen expresa la idea de la duplicidad y la co-presencia de las imágenes reveladas y no-reveladas en el mundo. En este sentido, la ontología cashinahua, que define las condiciones del ser y no-ser, es totalmente dependiente y asociada al proceso perceptivo real en el que un agente particular está involucrado. Una de las razones por las que mis primeras tentativas de asociar nombres particulares a unidades específicas de diseño no tuvieron éxito, se debe al hecho de la alternancia cinética entre fondo y figura de las imágenes. Otra razón fue que los cashinahua no le dan nombre solamente a las unidades, sino también a los padrones globales, a relaciones entre unidades y a la atribución del diseño en un soporte. Así como no existe una piel que no cubra un cuerpo, el diseño sin un soporte no tiene sentido en la estética amerindia. Observamos, de esta manera, que lo que le sucede con los diseños también sucede con el conocimiento en general: así como los diseños, el conocimiento necesita un cuerpo y un contexto propio como soporte y razón de ser. Es el soporte, así como el grafismo en sí, que transporta la propiedad del diseño. Para que un diseño sea propiamente un diseño (kuin) depende no solamente de sus calidades inherentes, sino sobre todo, del contexto: depende de quién pinta, qué y cuándo.

Otra consecuencia del perspectivismo en el arte y en la percepción en general es que la tradicional oposición entre apariencia y esencia, o entre realidad e ilusión, no tiene más sentido. Toda percepción tiene algún tipo de existencia específica propia. Esto no significa que las imágenes y los cuerpos ocupen la misma posición en la ontología cashinahua. La diferencia entre tipos de percepciones es producida al interior de un marco de referencia que toma en cuenta los distintos estados del ser. Uso "estados del ser" y no "estados de conciencia" porque de este modo evitamos el peligro de inadvertidamente oponer mente a cuerpo.

El estado del ser relaciona el estado del cuerpo y el estado de la mente. Por eso, entre los cashinahua cuando alguien ve fantasmas, o yuxin, u otras apariciones que no pertenecen a la esfera de la percepción cotidiana, nadie cuestiona el hecho de que esté realmente viendo alguna cosa: si la percepción es o no una ilusión, es decir una "alucinación", no será objeto de discusión. Etimológicamente, tener alucinaciones significa percibir (por medio de uno o más sentidos) lo que no existe en la "realidad". El concepto de "alucinación" no existe en la lengua cashinahua porque la concepción y percepción de "realidad" es radicalmente diferente.

El concepto cashinahua más cercano de nuestra noción de "ilusión" y "alucinación" podría ser "mentira" (txaniki), y según la seriedad de la experiencia, "broma -juego" (bcyuski). Cuando se dice que una persona o un espíritu del bosque estaba solamente "bromeando" no se espera ninguna consecuencia peligrosa. Mentir, por otro lado, puede ser más peligroso. Son los extranjeros, engañadores y los espíritus, los que mienten y engañan. Engañar es un método común usado para distraer y guiar a las personas que andan solitas, inadvertidamente, por caminos en 
que se extraviarán, haciendo que pierdan la orientación y la capacidad de volver al mundo conocido.

Es importante resaltar que el que "miente" sobre las percepciones que no se encajan en el mundo cotidiano de los cuerpos sólidos es, por lo general, no una persona que vio algo o contó lo que vio a uno de sus compañeros, sino un agente que produjo el fenómeno percibido. Estos agentes, llamados yuxin, son seres indefinidos y cambiables, sin un cuerpo sólido pero con la capacidad de producir imágenes, apariciones que asustan y confunden a los humanos.

Algunos de estos seres, los más poderosos llamados yuxibu (-bu es el pluralizador de yuxin, indican la multiplicidad y magnitud, concebida en términos de poder), tienen tanta potencia que son capaces de producir imágenes hasta transformarlas en lo que desean. Estos seres tienen la cualidad de aplicar golpes y engañar a los humanos, capturándolos y transfiriéndolos a otro mundo: un mundo percibido y vivido diferentemente. Una imagen usada para expresar el sobrepaso de esta frontera es la del yuxin "que exprime la savia de una planta medicinal en los ojos de una persona y la transporta a su propia aldea".

De esta concepción resulta que lo que debe ser determinado para comprender un caso extraordinario de percepción es un estado específico del ser (tanto del cuerpo como del "alma") perceptor, así como la calidad del ser percibido y del contexto de la percepción. La persona puede estar enferma o melancólica, o puede estar en proceso de volverse un chamán. Puede también estar en un estado perfectamente normal, pero el contexto puede ser propicio para que los fenómenos normalmente invisibles se manifiesten al caer la noche, o durante una tempestad con relámpagos. Otro contexto en el que se puede percibir las imágenes invisibles es durante el ritual de ingestión de ayahuasca.

Estos ejemplos señalan que las diferentes posibilidades de percepción están relacionadas a estados particulares del ser. Algunos de estos estados del ser implican tal alto grado de imitación y entrada en contacto con la alteridad, incluyendo el cambio de acción y de la forma corporal, de tal manera que poco sobra de lo que podríamos llamar el "yo real", inmerso en la actividad corporal, en la interacción social y en las rutinas diarias. El llamado del bosque, con sus animales/yuxin: queriendo transformar a su víctima seducida en uno de ellos, es de igual peligro que el llamado de la ciudad con su bebida, su aguardiente, y su fascinante variedad de habitantes (nawa).

En este sentido, no es por casualidad que hoy en día los espíritus del bosque, que surgen en los viajes visionarios, son desafiados por las excitantes y peligrosas visitas, y las visiones de visitas a las ciudades de Sao Paulo, Lima, o a las más distantes ciudades de los huxu nawa, los "blancos extranjeros" (europeos y americanos). 
Por lo tanto, la vida y el ser de una persona son vistos como un proceso dinámico, con caminos e identidades posibles de ser seguidos y asumidos. De acuerdo con estas múltiples posibilidades de existencia, y peligros de transformación en alteridades incontroladas, la tarea de la comunidad como un todo, y de los adultos en particular, es encargarse de la producción de la vida en la comunidad, buscando transformar a los jóvenes en huni kuin, seres humanos propiamente dichos, guiándolos a través de la multiplicidad de percepciones, emociones y actividades posibles y presentes en el mundo envolvente, modelando sus propias criaturas en seres de una clase, nukun yuda, "nuestro cuerpo".

De esta manera, los adultos cashinahua trabajan para educar a sus hijos con "cuerpos pensantes", siempre "pensando en sus cuerpos (yuda)" (sus propios cuerpos y la comunidad como un "cuerpo social"). Esto significa que sus cuerpos cargan pensamiento y sentimientos de pertenencia en función de la comida, de los cuidados corporales, las memorias y los valores compartidos durante la vida. Cuando están lejos de casa, los viajeros sienten falta de la comida, de la comensalidad, las historias y los cuidados de las personas con quienes compartieron y vivieron la infancia.

Los cashinahua admiten, al compararse con los "blancos" que su educación es permisiva ya que el uso de la fuerza y la agresividad es evitada a toda costa. La autonomía y el libre arbitrio son respetados, aun cuando se trata de niños. Entre adultos, las peleas, o el hablar alto y el dar órdenes, no son toleradas. Los conflictos son resueltos por medio de la evitación, y el castigo más severo es el ostracismo (Kensinger 1986b). Un arma eficiente para imponer los valores del compartir y de la reciprocidad es el chisme. Las decisiones son tomadas solamente cuando las partes involucradas concuerdan, y cuando el acuerdo parece imposible el grupo disidente decide irse para dejar las cosas "enfriar", o intentar vivir en otra parte. Esta moral social explícitamente pacifista e igualitaria es común en muchas sociedades amazónicas, y es un factor importante del modo cómo estos pueblos se definen como diferentes de otros pueblos, especialmente de los narva (no indios).

De esta manera, el proceso de creación y de invención permanente de una comunidad específica y de un estilo de vida, es realizado por medio de una continua negociación entre lo nuevo y lo viejo para hacer frente a los cambios de contexto de las nuevas oportunidades que surgen, y de las antiguas que desaparecen en un mundo en permanente transformación.

Esta constante reinvención de la identidad frente a la alteridad envolvente es otra manifestación de la concepción específica que los Cashinahua tienen de la noción de identidad y de diferencia. Si la identidad implica la alteridad, el perspectivismo se vuelve el elemento de relación entre estas nociones, volviéndolas interdependientes e intercambiables. 


\section{Bibliografía}

Århem, K.

1993 Cosmic food web: Human-nature Relatedness in the Northwest Amazon. (Draft version, $\mathrm{ms}$ )

Baer, G. ; Langdon, E.J. (eds.)

1992 Portals of Power. Shamanism in South America. Albuquerque: University New Mexico Press.

Barthes, R.

1980 La Chambre Claire. Paris: Seuil.

Becker, A.

1995 Body, Self and Society. The view from Fiji. Philadelphia: University Pennsylvania Press.

Belaunde, L. E.

1992 Gender, commensality and community among the Airo-Pai of West Amaz (Secoya, Western-Tukanoan speaking). Tesis de doctorado, London School a Economics.

Calavia, O.S.

1995 O nome e o tempo dos Yaminazua. Etnologia e história dos Yaminawa do Rio Tesis de doctorado, São Paulo: USP.

Capistrano de Abreu, J.

1914 (1941) (2 ed.). Rã-txa hu-nii-kui : A Lingua dos Caxinauás do Rio Ibuaçú.

Cardoso de Oliveira, $\mathrm{R}$.

1991 Razño e afetividade. O pensamento de Lucien Lévy-Bruhl. Campinas: Unicam (Centro de Lógica, Epistemologia e História da Ciência)

Carneiro da Cunha, M.

1978 Os mortos e os Outros. São Paulo: Hucitec.

Chaumeil, J-P.

1983 Voir, Savoir, Pouvoir. Le chamanisme chez les Yagua du Nordest Péruvien.

Clastres, P.

1974 La société contre l'État. Paris: Les Éditions de Minuit.

1982 Arqueologia da Violência. São Paulo: Brasiliense. 
Crocker, J. C.

1977 My brother the parrot. The social use of metaphor: essays on the anthropology of rhetoric, ed. J. D. Sapir \& J. D. Crocker, 164-92. Philadelphia: University of Pennsylvania Press.

1985. Vital Souls: Bororo cosmology, natural symbolism and shamanism.Tucson: University of Arizona Press.

Da Matta, R.

1976 Apinayé. Um mundo dividido. Petropolis: Editora Vozes.

Dawson, A.

1975 Graphic Art and Design of the Cashinahua. En: Dwyer, J.P.(ed.). The Cashinahua of Eastern Peru. Haffenreffer Museum of Anthropology.

Deleuze, G.

1988 Le Pli. Leibniz et le Baroque. Paris: Minuit.

Descola, Ph.

1987 La Nature Domestique: symbolisme et praxis dans l'écologie des Achuar. Paris: Editions de la Maison de Sciences de L'Homme.

Deshayes, P. ; Keifenheim, B.

1982 La conception de l'Autre chez les Kashinazua. Tese de dotourado, Université de Paris VII (publicado en 1994. Penser L'autre. Chez les indiens Huni Kuin de l'Amazonie. Paris: L'Harmattan.)

Dumont, L.

1980 Homo Hierarchicus. Paris: Plon.

Erikson, Ph.

1986 Altérité, ta touage et anthropophagie chez les pano: la belliquese quête du soi. 1992 Uma singular pluralidade: a etnohistória pano. História dos Índios do Brasil. 1995 Reseña de libro de Deshayes y Keifenheim. ms.

Fernandes, F.

1970 A função social da guerra na sociedade TupiTupínamba. São Paulo: Pioneira - EDUSP.

Goldman, I.

1963 (1979). The Cubeo. Indians of the Northivest Amazon. Urbana: The University of Illinois Press.

Goldman, M.

1994 Razño e Diferença. Sobre Lévy-Brulhl. Rio de Janeiro: Editora da UFRJ. 
Gonçalves, M. A.

1995 Um mundo Inacabado. Cosmologia e sociedade Pirahà. PhD Thesis. PPGAS. Museu Nacional, UFRJ. RJ.

Goodman, N.

1978 Ways of Worldmaking. Indianápolis: Hackett Publishing Company

Gow, $P$.

1988 Visual Compulsion; Design and Image in Western Amazonian Art. Revindi. 19-32.

1991 Of Mixed Blood. Kinship and History in Peruvian Amazonia. Oxford, Oxford University Press.

Guss, D.

1989 To Weave and Sing. Art, Symbol and Narrative in the South American Rain Forest. Berkeley, Los Angeles, London: University of California Press.

Ingold, $\mathrm{T}$. (ed.)

1996 Aesthetics is a cross-cultural category. En: Key Debates in Anthropology:249293.

Isacsson, S. E.

1993 Transformations of Eternity. PhD. Thesis. Göteborg: University of Göteborg.

Jackson, M.

1989 Paths towvard a Clearing, Radical Empiricism and Ethnographic Inquiry. Indiana: Indiana University Press.

Keifenheim, B.

1990 Nawa: Un concept clé de l'altérité chez les Pano. L'Homme, 76: 79-94. Paris 1992 Identité et Altérité chez les Pano. En: L'Homme, 78(2): 79-93. Paris

Kensinger, $\mathrm{K}$.

1977 Cashinahua Notions of Social Space Time and Social Space. Kaplan, J. (ed. Social Time and Social Space in Lowland South American Societies. Actes do iz Congresso Internacional de Americanistas. Paris.

1986 (1988). Invisible People: Ostracism in Cashinahua Society. Randolph et al Ed. Dialetics and Gender, Anthropological Approaches. London: Westview Press Boulder and London.

Lakoff, G.

1990 Women, Fire, and Dangerous Things: What Categories reveal about the Mind. 
Lagrou, E. M.

1991 Uma Etnografia da Cultura Kaxinazuá: entre a Cobra e o Inca. Dissertação de mestrado. PPGAS. UFSC.

1993 Resenha do artigo de Peter Gow: «Visual compulsion: Design and Image in Western Amazonian Cultures». Antropologia em Primeira mão. Florianópolis, UFSC/PPGAS.

1995 Hermenêutica e etnografia- uma reflexão sobre o uso da metáfora da textualidade para «ler» e «inscrever» culturas ágrafas. Revista de Antropologia, 37: 35-55, São Paulo, USP.

1998 Caminhos, Duplos e Corpos. Uma abordagem Perspectivista da identidade e alteridade entre os Kaxinazva. Tese de doutorado, São Paulo: USP. (Traducido da Versão inglesa: Cashinahua Cosmovision. A perspectival Approach to Identity and Alterity. PhD., University of St. Andrews).

Lévi-Strauss, C.

1955 (1973). Tristes Tropiques. Paris: Plon.

1958 (1974). Anthropologie Structurale. Paris: Plon.

1991 Histoire de Lynx. Paris: Plon.

Lima, Tânia Stolze

1996 O dois e seu múltiplo: reflexões sobre o perspectivismo em uma cosmologia TupiTupí. Mana, 2 : 21-47.

Marriott, McKim.

1976 Hindu transactions: diversity without dualism. B. Kapferer, ed. Transaction and Meaning. Philadelphia: ISHI Publications (ASA Essays in Anthropology, 1).

Maybury-Lewis,D.

1979 Dialectical Societies: the Gê and Bororo of Central Brazil. Cambridge, Mass., Harvard University Press.

McCallum, C.

1989 Gender, Personhood and Social Organization amongst the Cashinahua of Western Amazonia. PhD. Thesis, London School of Economics. University of London.

Ortony, A. ed.

1979 (1993). Metaphor and Thought. Cambridge, Cambridge University Press.

Overing, J.

1975 The Piaroa. A people of the Orinoco basin. A study in Kinship and Marriage. Oxford: Clarendon Press.

1984 «Dualisms as an expression of difference and danger: marriage exchange and reciprocity among the Piaroa of Venezuela». Kensinger, K. (ed.) Marriage Practices in Lozvland South America. Urbana/Chicago, University of Illinois Press 
1985 There is no end of evil: the guilty innocents and their fallible god. ed. Parkin: 244-78. Blackwell Publications.

1986 Images of cannibalism, death and domination in a 'non-violent' society. Journal de la Société des Américanistes, LXXII:133-56.

1987 Translation as a creative process: the power of the name, Holy, L., ed. Comparative Anthropology: 70-87. Oxford: Basic Blackwell.

1988 Personal autonomy and the domestication of self in Piaroa society, Jahoda, G. \& Lewis, I. M.:169-192. Acquiring Cultures: cross-cultural studies in child development. London, Croom Helm.

1989 The aesthetics of production: the sense of community among the Cubeo and Piaroa. Dialectical Anthropology 14:159-75.

1990 The shaman as a maker of worlds: Nelson Goodman in the Amazon. Man (N.S.) 25: 601-19.

1993 Death and the loss of civilized predation among the Piaroa of the Orinoco Basin. L'Homme 126-128. Paris.

Ricoeur, P.

1981 Hermeneutics and the Human Sciences. Cambridge, Cambridge University Press.

Roe, $\mathrm{P}$.

1987 Impossible Marriages: Cashi Yoshiman Ainbu Piqui (The Vampire Spirit Who Ate a Woman) and Other Animal Seduction Tales among the Shipibo Indians of the Peruvian Jungle. Paper apresentado no Fifth Internatinonal Symposium on Latin American Indian Literatures (LAILA), Ithaca, New York.

Seeger, A.; Da Matta R. ; Viveiros de Castro, E.

1979 A construção de pessoa nas sociedades indígenas brasileiras. Boletim do Museu Nacional, 32:2-19.

Shanon, B.

1993 The Representational and the Presentational. An Essay on Cognition and the Study of Mind. London, Harvester Wheatsheaf.

Strathern, M.

The Gender of the Gift.

Taussig, M.

1993 Mimesis and Alterity. A particular history of the senses. New York/London, Routledge. 
Thomas. D.

1982 Order without government: The Society of the Pemon Indians of Venezuela. Urbana: University of Illinois Press.

Tounsley, G.

1988 Ideas of Order and Patterns of Change in Yaminahua Society. Tesis de Doctorado. Cambridge University.

Vilaça, A.

1992 Comendo como gente. Formas do Canibalismo Wari'. Rio de Janeiro: Editora UFRJ.

Viveiros de Castro, E.

1986 Os Arazueté, os deuses canibais. Rio de Janeiro, Zahar\& Anpocs.

1992 From the Enemy's Point of View. Chicago, Chicago University Press.

1993 "Alguns aspectos da Afinidade no Dravidianato Amazônico». Viveiros de Castro, E. \& Carneiro da Cunha, M. (eds.). Amazonia. Etnologia e História Indigena. NHII/USP/FAPESP.

1996 Os pronomes cosmológicos e o perspectivismo ameríndio. Mana 2: 115-144.

Wagner, R.

1986 Symbols that stand for themselves. Chicago/London, University of Chicago Press. 